\title{
Homoterrorism: Definition, Application, Subversion
}

\author{
Angelos Bollas
}

\section{Introduction}

On Friday, September 21, 2018, news reports on Greek corporate media announced the death of a man who had allegedly attempted to rob a jewellery store. The media announcement was accompanied by video footage in which two civilians were shown violently attacking the alleged thief while the latter was attempting to escape the jewellery store. A little later, the alleged thief was announced dead. This is the case of Zak Kostopoulos who was lynched in his attempt to escape a jewellery shop where he had found shelter from a threat that, to this day, remains unknown. Zak was lynched literally and figuratively by the jewellery shop owner and his associate, by the bystanders, and by all corporate media. In this paper, homoterrorism is proposed as a construct that can describe hegemonic attempts to portray certain domestic non-heterosexual identities, practices, and cultures as abject in an attempt to (re)define a society's national sociodicy. The argument is that homoterrorism provides an understanding of extreme acts of violence against the non-heterosexual Other, such as in the case of Zak Kostopoulos's murder, especially when such acts are framed as essential to the precipitation of national cohesion. Further to this, the paper draws on theories about social media and their potential for political and social change, and it argues that Twitter activism can become a way to challenge homoterrorism.

\section{From Homonationalism to Homoterrorism}

Initially coined by Jasbir Puar (2007), homonationalism refers to the political practice by which supporting LGBTQI+ rights functions as a tactic to enforce nationalist pride, and supposed progress in relation to LGBTQI+ matters is used to alienate a people against the backward Other, the countries which do not support LGBTQI+ individuals and their rights. "Images of exuberant gay sexuality and celebration have been enlisted as icons of the kind of freedom the so-called 'West' has to offer, to contrast with the "backwardness" and repression that are attributed to Easter Europe, the Islamic world, and immigrants" (Drucker 2016). So, homonationalism is yet another political means through which a people's pride of their national, religious, and racial identity is confirmed, but it has also been used as reason to encourage and promote racist ideologies. As a theoretical tool, homonationalism, drawing on Duggan's (2003) concept of homonormativity, highlights not only the conflation of nationalist ideologies and LGBTQI+ rights, but it allows an understanding of the processes whereby LGBTQI+ people are led to ascribe to such ideologies. As an effect of neoliberal politics, homonormativity contributes to the success of capitalism. On the one hand, it ensures fewer people are marginalised and, therefore, more people are actively contributing to the market. On the other hand, though, it also contributes to the stigmatisation of those who might disrupt social order and cohesion which, in turn, might result in a reduction of market profits. 
At the same time when Puar (2007) observes homonationalist tendencies and practices in the US foreign policy, Francoeur (2007) observes increased surveillance and punishment of LGBTQI+ immigrant activists in places such as New York and other US metropolitan areas. He argues that the federal government uses post-9/11 strict policies against illegal immigrants as a "[...] deliberate attempt to leverage terrorism as the new ideological exclusion and LGBT immigrants as terrorists" (p. 72). Homoterrorism is used by Francoeur (ibid.) to describe internal policies that aim to literally get rid of those immigrant individuals or groups who challenge normative notions of family, marriage, and society. A different use of the term is offered by Płonecka (2017) who explains that in the Polish parliament homoterrorism is used to describe LGBTQI+ activists who are seen as terrorists for trying to defile Polish society by advocating equal rights for LGBTQI+ citizens.

In this paper, I wish to propose homoterrorism as a variant term to homonationalism in that rather than being used as a means to further alienate foreign individuals, societies and cultures, homoterrorism describes a hegemonic attempt to portray certain domestic non-heterosexual identities, practices, and cultures as abject in an attempt to (re)define its national sociodicy. As such, homoterrorism is both causative and symptomatic of heteronormative and homonormative politics and culture. Thus, homoterrorism is not relevant to all those who identify as non-heterosexual. Rather, it relates to those whose non-heterosexual identities and practices are perceived to be disrupting social order. In other words, so long as one has the potential to be a beneficial and contributing member to a society's market-production activities, they are not potential subjects of homoterrorist concerns. At the same time, it is important to consider the relationship between social cohesion and market growth which, for neoliberal ideologies, is a twofold one. On the one hand, social cohesion is viewed as an opportunity for people to recover from the demands of capitalism and recharge so that they can return afresh in production mode (Jenson 1998). On the other hand, social cohesion and economic development are presented as intertwined with the former being portrayed as a factor for the latter and vice versa (Jaffe and Quark 2006). It is, therefore, within a neoliberal nation's best interests to promote national cohesion. As a phenomenon, homoterrorism does not only describe processes of Othering, but it aims to provide an understanding of extreme acts of violence against the non-heterosexual Other, especially when such acts are framed as essential to the precipitation of national cohesion. Here, the non-heterosexual Other is not perceived as threatening to a person's - or the society's, for that matter - beliefs, values, norms or symbols. Therefore, an act of violence enabled by the fear of homoterrorism is not to be understood as similar to a hate crime. Here, the non-heterosexual Other is perceived as a threat to a nation's social cohesion. So, homoterrorism enables the framing of an act of violence as inevitable and heroic.

Further to that, it is important to clarify that homoterrorism does not refer to instances of homophobic behaviour, nor does it refer to absolute discrimination of non-heterosexual identities and practices. Rather, it aims to explain extreme acts of violence against specific non-heterosexuals in societies and countries which have made constitutional and legal progress in recognising, fully or in part, equal rights for LGBTQI+ individuals. Also, homoterrorism is not proposed as a term to describe the act of violence per se, but it aims to provide a framework within which this act is presented as justified. Therefore, the proposed locus of homoterrorism is corporate media and, in particular, news reports. However, even though homoterrorism encourages social cohesion by framing certain identities and practices as threatening to a nation's sociodicy, this paper does not aim to endorse an a priori link between media and the creation or promotion of a collective identity. Schlesinger (1991) argues that such a linkage has to be demonstrated "[...] through detailed conjunctural analysis and comparison both diachronically and synchronically" (p. 307). Such a demonstration, although important, is beyond the scope of this paper.

Situating homoterrorism in media practices and news report discourse echoes Herman and Chomsky's (1988) propaganda model in that it links systemically biased discourses (re)produced in news reports with the political and economic interests of those in power. Media's reach enables them to contribute to the construction and promotion of a national image (Samoilenko 2020). In addition, news reports communicate an agenda of legitimate concerns that the citizens of a particular nation should have. Botan (2018) observes "[...] when a group of public reaches consensus on a shared image, that image can serve both as a kind of shorthand interpretation that facilitates common decisions and a binding agent that allows large groups of people to become [...] interpretive communities" (p. 90, emphasis in original). According to this, homoterrorism refers both to the framing of a particular image as threatening and to the facilitation of decision-making with regards to how citizens of a nation should feel and act in response to such 
an image. In other words, homoterrorism enables citizens to recognise all non-conforming non-heterosexual identities and practices as potentially threatening and, in turn, all violent acts against such identities and practices as justified.

To illustrate how homoterrorism as a frame is used by corporate media as a means through which a national image is (re)defined and extreme acts of violence toward non-heterosexual individuals are justified, the following section analyses as case study the literal and figurative lynching of Zak Kostopoulos in Athens, Greece. In what follows, I examine the case of Zak's murder as it was presented in news reports by all corporate media in Greece. This explains why at the early parts of the examination that follows, one reads 'death' rather than 'murder' or 'lynching' when it comes to describing what happened on September 21, 2018 in Athens, Greece. The focus of the following section is not to reproduce facts about the murder of Zak in a journalistic manner. Rather, the section aims to illustrate homoterrorism at work, showing both how through homoterrorism Greek society redefines what it means to be Greek, what is the acceptable Greek identity, as well as how fear of queers (here 'queers' is used to refer to non-conforming non-heterosexual individuals and practices) was used to support extenuating circumstances for the perpetrators in the eyes of the society. At the time of writing this paper, the case has not reached the courts of justice.

\section{Homoterrorism and the Case of Zak Kostopoulos's Lynching}

On Friday, September 21, 2018, Greek news media announced the death of a man who had allegedly attempted to rob a jewellery store. The media announcement was accompanied by video footage in which two civilians were shown violently attacking the alleged thief while the latter was attempting to escape the jewellery store. A little later, the alleged thief was announced dead. The next day, the identity of the victim was made public. Along with his name, Zak Kostopoulos, the following characteristics were being communicated by the media to describe him: LGBTQI+ activist, HIV activist, HIV positive, and drag queen, Zackie Oh!. Further to the identification of the victim as LGBTQI+ and HIV positive, Greek media also characterised the victim as drug addict, and they emphasised the fact that he attempted to rob the jewellery shop with a knife, suggesting that he was not only about to rob a store, but he could have caused more serious damage. Words that were often used to describe him by all major TV news outlets in Greece included "faggot", "AIDS-patient", "junkie" who was "trying to break in and steal" so "he was asking for it" and "it served him right to die like this" (Poulopoulou 2019).

News reports did not focus at all on the fact that an alleged robber, though still a human, was beaten to death in the city centre of the country's capital. The incident took place in the middle of a working day with pedestrians recording the scene on their phones. Nobody helped. Nobody asked the two men who beat Zak to death to stop. This did not make the news, though. The video that shows, as graphically as possible, Zak's death was being broadcasted on loop for days. In that video, we can see two men beating violently an already unconscious man, Zak, and we can also see those bystanders who watch the incident not with terror, but curiosity. The coverage of the incident went out of proportion when, instead of reporting on developments with the case, lifestyle-type of shows started publishing polls asking the public whether they would rather have as their neighbour an ex-criminal or an LGBTQI+ person.

To understand how this incident illustrates homoterrorism instead of, for example, a violent murder of someone who was believed to attempt armed robbery, one must examine the way Zak, the alleged armed robber, was framed in relation to the jewellery shop owner, as well as the bystanders. In doing so, it becomes clear that visual evidence contradicts narrative description, and yet no news report commented on that. The visual evidence broadcasted by all news reports show a man, Zak, being in a jewellery shop. We do not see him carrying a knife, and we do not see him touching, let alone stealing, anything from the shop. A few seconds later, we see people having gathered outside the shop, staring at Zak. He seems distressed, unable to open the main door to leave the shop; instead, he tries to break the shop window to escape. To do so, he attempts to use a fire extinguisher which he found in the shop. However, he is evidently too weak to even hold the fire extinguisher. He continues to try to escape through the shop window and, at that point, two men approach the shop window, and they start kicking it until it breaks. What follows includes them dragging Zak out of the shop through the half-broken window and beating him to death. Needless to say, Zak does not fight back, not once. 
Anyone watching the scene could see a helpless skinny man with no strength or willingness to hurt anyone being brutally beaten by two big guys outside a shop in a busy Athenian street. However, from the moment this footage was broadcasted by the Greek media, a different picture was painted. Zak was not referred to by name. Instead, he was referred to as 'robber', 'armed', 'junkie', 'queer' and 'dangerous'. The jewellery owner, who was one of the two men who beat Zak to death, was also not referred to by name. He was referred to as voıxoxu̇@s [/noikokúres/], literally translated in English as homemaker or landlord, but ordinarily used to describe a traditional and respectable man who is devoted to family life, who minds his own business, and whose actions are driven in relation to providing for and protecting his own family and his people. While the footage was playing on repeat and more and more people saw that Zak was not a threat to anyone, that he could not even defend himself, and that the two men could have just held him and let the police take over, the media started making further revelations with regard to Zak's identity. In particular, they highlighted that he was gay, HIV positive, and a drag queen. These characteristics were not used to represent him as a victim. Rather, they were presented as justifications for his victimisation. Not only was he presented as insufficiently masculine and, therefore, less able to contribute to the nation's production; but also, being HIV positive meant that he was contributing to the stagnation of the country's resources by receiving disability benefits. In other words, Zak was framed to be a double threat to the nation. Neither did he fit the norm as to what a man should be and act like, nor did he contribute to the country's economy.

Further to that, Zak's identity was presented in opposing terms to the identity of the jewellery owner. However, a closer examination of the footage allows us to see that Zak was also framed in relation to the bystanders to the scene. This was not overtly discussed by news media, but all footage presents the beating of Zak as a spectacle for the bystanders' appetite. In each video, we see about 20 people gathered around and recording the scene on their phones. Other than illustrating the inhumane nature of our generation, this is significant in that arguably the crowd's inaction suggests endorsement. The beating of Zak is not challenged by the crowd. His beating becomes lynching, and part of society is there to bear witness. Watching this video on the news, then, does not leave much room to question the actions of the two men. If there are so many people present in the scene and nobody does anything to help Zak or stop the two men, it must be that these two men are right, and that the helpless man on the floor must have done something so wrong that justifies the brutality of his beating.

To further understand this through the lens of homoterrorism, one needs to consider the sociocultural context of the incident. In August 2018, Greece exited the final bailout programme, which - at least in theory - marked the conclusion of a financial crisis the onset of which is traced to 2007 by some and to 1974 by others (CFR n.d.). At the time of the incident, Greek society was devasted financially with each major and minor social institution being on the verge of collapse. This does not stand as justification for the perpetrators' actions. Rather, it allows us to understand the significance of the connotations attached to the label voxoxvons with which the jewellery owner was being presented. A voxxoxigns is now more than a traditional and respectable man who is devoted to family life, who minds his own business, and whose actions are driven in relation to providing for his own family. At that point in time, a voxxoxigns symbolised at once both the longing for a lost Greek society and the attempt to re-establish such a society along with a restored national identity and national pride.

This is significant because Zak was not presented as a homosexual who insulted core heteronormative ideals. This would not have been possible with a government that adopted homonormative politics by means of conservative but seemingly progressive legislations protective of - some - gay rights such as, recognition of civil partnership for gay and lesbian couples. Zak was not framed as a gay man. Rather, he was framed as a bad queer, the worst type of gay man. For a society like the Greek one, his HIV positive status was translated in terms of sexual promiscuity, reckless behaviour, and a possible threat to others. His being a drag queen was translated in terms of mental disorder. One cannot but wonder what relevance his HIV positive status, his art as a drag queen, and his preoccupation with HIV/ AIDS activism had in relation to the alleged robbery, other than to portray him as a threat not only to the jewellery owner, but to core Greek ideals. Defining Zak as a threat to Greek ideals enabled the (re)definition of what these ideals were. The framing of Zak as homoterrorist did not only serve as an extenuating circumstance that justified the brutality with which he was attacked, but it also served as an excuse to redefine and strengthen core national, in this case Greek, ideals. The unfathomable effects of homoterrorism as a phenomenon and a practice are concentrated in 
Zak's literal and figurative lynching.

Days following his murder, Zak remained the main interest of corporate media productions. However, it is not his murder that preoccupied lifestyle-type of TV shows; it was him as a person. In a TV show that fashions itself after The Oprah Winfrey Show, the host published a poll asking her audience to decide whether they would prefer to have as a neighbour someone like Zak to a convicted criminal. Days after Zak's murder and before there was any kind of evidence confirming that Zak indeed attempted to rob the jewellery shop, that he was indeed carrying a knife or that he was indeed a threat, corporate media took the case to their hands but rather than focusing on analysing the footage they had, they focused on identifying who is and who is not a threat to Greek society. After days upon days of continuous framing of Zak as a national and social threat, the results of the polls were not surprising: Greeks - or at least those who responded to the poll - were definitely determined not to have someone like Zak as a neighbour. However, it is not the results of the poll that really matter. What matters is that this kind of a poll actually happened. Whether people had chosen Zak or a convicted criminal as their preferred type of neighbour is of minor importance. What is of importance, if not terror, is that the incident with Zak was seen as reason for Greek society to define who is acceptable as neighbour and, by extension, who is acceptable as citizen of the Greek state. Homoterrorism allows a people to fear those whose sexual identities and practices differ from the norm, and through fear, it enables them to construct a sense of similarity among them, leading to the emergence of definitions about who is the accepted citizen and who is not (Phelan 2001). The remaining part of this paper examines the possibility of social media to challenge bomoterrorism and queer neoliberal understandings of citizenship.

At the same time when corporate media were using homoterrorism to frame the case of Zak's murder, Zak's fellow activists and drag queens started the \#justice4zakzackie campaign (initially as \#justiceforzak) on social media as a means of challenging what was broadcasted by corporate media, generating a counternarrative. As a result of the success of this campaign, the Greek Minister of Citizen Protection, Amnesty International, the Prosecutor of the Greek Supreme Court, the Greek Ombudsman's mechanism, and the Greek Prime Minister were mobilised, and they ordered further and thorough investigations. To date, the investigations have proven that Zak was not intoxicated and that, based on evidence from CCTV cameras, he had taken the knife from a café he had been prior to the incident in question in order for him to protect himself from a possible attack by another person in that café. He, then, left the café and took shelter in the jewellery store; he did not break in to steal anything. He broke in because he was scared. The police officers and the two individuals who beat Zak up to his death are still free.

The case of Zak Kostopoulos presented above aims to illustrate how homoterrorism enables acts of extreme violence to happen and to be justified by a society. The discussion that follows uses the \#justice4zakzackie campaign as an example that illustrates Papacharissi's (2015) argument about the facilitation of new forms of political activism by digitally networked technologies. In doing so, I suggest that activism enabled through social media can challenge phenomena such as homoterrorism by enabling an alternative to corporate media narrative to emerge and circulate among a big proportion of the population. As such, this form of communication renders possible not only the subversion of corporate media narratives, but also of hegemonic phenomena that contribute to the Othering of individuals, situations, and contexts that do not serve neoliberal political agendas. First, I discuss Papacharisi's argument and then, I apply her theories on the \#justice4zakzackie campaign justifying its success and using it as an example of a way to challenge homoterrorism.

\section{Twitter Activism as Subversion of Homoterrorism}

Digital networks have allowed the emergence of hybrid forms of news to occur, initially because of users' mobile autonomy. This refers to having the ability to choose with whom, from where, and how to connect to what is happening around the world (Hay 2003), and, most importantly one could argue, because they encourage the production of user-generated arguments which, in turn, become social conversations on what becomes news by enabling people to both talk back to and challenge corporate media accounts (Papacharissi 2014). Schonfield (2010) examines the role of platforms like Twitter in producing collaborative storytelling and news co-creation and curation, and Bruns and Highfield (2012) argue that these affordances have transformed these platforms into an alternative 
to corporate/dominant news media. In situations of social or political crises, corporate/dominant media broadcast news generated by online users who not only report but also discuss what is happening with a particular situation (Howard 2011). It has been observed that platforms like Twitter, for example, are not only used to report news but, more importantly, they are used to ensure that news are being reported by dominant media accurately and when this is not happening, these platforms are used to separate rumours from facts (Vis 2013). Often-marginalised voices are given the opportunity to report, follow, or correct information that is being broadcasted which enables them not only to influence the dynamics of a particular crisis but also to influence the way history is written (Hamdy 2010).

News streams generated collaboratively by online users through social platforms combine traditional broadcasting conventions and storytelling practices (Papacharissi 2014). This results in streams where objectively reported news and interpersonal conversation are combined and produce emotionally charged news reports. These streams are not produced so that they replace dominant media; they "[...] reconcile the more deliberate and self-conscious storytelling [...] with the additive and participatory nature of [...] storytelling practices, producing a form [...] we might understand as digital" (p. 5). Papacharissi (ibid.) employs affect - subjectively experienced emotion - as a way of understanding and examining these co-generated streams of news on digital platforms such as Twitter.

"If we understand affective news streams not just as informative, but as collectively-generated, pluralistic arguments on what should be news, and how news stories should be told, we may interpret affective news gestures as indicative of political statements of dissent with a mainstream news culture, and the agendas that culture cultivates" (p. 7).

It is important to note that affect is not an exclusive characteristic of digital platforms. Rather, it is present in news produced by corporate media, as well. Furthermore, corporate media employ tactics that imitate aspects of digital platforms, such as polling audiences. However, the two differ in that in digital platforms, affective news streams do not undergo scrutiny like corporate media news do. Instead, they tend to emerge as responses to what is presented, or silenced, by corporate media. Digital networks, in other works, not only allow users to become reporters and co-create news, engage with the news while they are reported, and correct the way facts are being reported by dominant news; they also provide users with space and power for political influence and social change. Colleoni (2013 cited in Papacharissi 2015) discusses many such stories whereby digital networks have provided a platform for affective engagement with the news in a manner that invites social change. Papacharissi (2015) argues that hashtags of campaigns linked to major movements are "[...] signifiers [...] open to definition, redefinition, and re-appropriation" (p. 2). This process is what allows people to create collaboratively generated stories and, as a result, make them transform from crowds to networked publics. These publics, she argues, "[...] assemble around media and platforms that invite affective attunement, support affective investment, and propagate affectively charged expression, like Twitter" (ibid.). Such digital media, though, do not encourage revolutions; they only provide crowds with a space where they can form publics. These public formations are unique to each situation. In other words, what drives those formations is not always the same. What unites them, though, is "[...] a public display of affect" (ibid.).

Papacharissi (ibid.) examines the concepts of pre-mediation, homophyli, Twitter's role in uprisings, and locality in order to further understand the ways in which the platform is used by publics and how this has affected political activism. Grusin (2010) used the term pre-mediation to explain "[...] the form that events take, before they turn into stories" (p. 3). Pre-mediation, according to Papacharissi (2015: 3), is an important feature of platforms like Twitter in that it encourages a drive for instantaneity in news reporting which often does not add substance but intensity. Homophyli refers to the tendency of people following like-minded others online (Weller et al. 2013). As a result, public awareness on issues of public affairs and of social nature is increased (Erickson, 2010) which, in turn, challenges political hierarchies, and it makes redistribution of power possible (Chadwick 2013). Jansen et al. (2009) discuss the role of Twitter as the electronic word of mouth news sharing which allows marginalised publics - and marginalised issues - to be heard. Finally, Yardi and Boyd (2010) argue that social connectivity is being enhanced by engagement with hashtags about local events. "In conversations around controversial topics, replies between likeminded individuals tend to strengthen group identity, whereas replies between different-minded individuals reinforce in-group and out-group affiliation" (Yardi and Boyd 2010, in Papacharissi 2015). 
The discussion so far focuses on the characteristics of platforms like Twitter that promote feelings of engagement (Van Dijck 2013). It is these feelings that encourage crowds, who would otherwise be disconnected from one another, to form networked publics (Howard and Hussain 2013). Such an online activity followed by offline mobilisation of these publics can "[...] bring about disruptions to the stability of powerful hierarchies [and] grant a movement momentum, which may accumulate over time" (Papacharissi 2015: 4). After the incident on Friday, September 21, corporate media portrayed Zak as a dangerous, homosexual, and HIV positive junkie who broke into a jewellery store and did not only attempt to rob it but, perhaps most importantly, as they reported, his presence alone could corrupt the Greek society as a whole (The Press Project 2018). By deploying affective means of engaging audiences, enabled through homoterrorism, corporate media engage in promoting a collective identity in response to Zak's identity. If it weren't for the \#justice4zakzackie hashtag, the case would have closed, the perpetrators would have been free, Greeks would have believed that they got rid of a miasma of perversion and moral corruption and that their national identity and pride has been restored.

The hashtag started off by members of the LGBTQI+ community who knew Zak and were willing to share their version of who he was and what he was capable and not capable of doing. The popularity of the hashtag grew, and more individuals joined the discussion. Some of them started sharing video footage they had recorded from their mobile phones while at the incident. Those videos became viral because they showed a very different scene to the one that was painted by corporate media. The result was that Ministers, the Prime Minister, and international organisations got involved and started monitoring the investigations closer. Online mobilisation was soon followed by protests on the streets and peaceful marches which added to the pressure on the authorities to examine the incident carefully and in a less biased manner. Since then, more videos and more facts have been released by the authorities all of which contradict the initial portrait of Zak painted by corporate media.

It appears that Zak was more than three noun phrases. Zak was a real human with family, friends, pets, dreams, aspirations, and rights. The \#justice4zakzakie hashtag campaign brought to light video footage from the bystanders which reveals a very different case to the one promoted by corporate news reports. Zak appears to be beaten by those two men without being able - or willing - to fight back and protect himself. When the police arrive, he does not resist. Yes, he is treated violently by the police, something that might have contributed to his death. Anny Paparousou, lawyer of Zak's family, reports to the Irish Times "He is clearly only half-alive but they cuff him from behind, making any attempt at resuscitation impossible" (Smith, 2020). Further to this, reports about the failure of authorities to properly seal the crime scene, as well as claims about a cover-up are continuously being reported on the \#justice4zakzakie hashtag. Zak's fingerprints were not found on the knife, and toxicological reports confirm that there were no traces of drugs in his body. None of this was reported on corporate news reports. For these media, Zak remains a threat to the social and national cohesion of Greek society.

The emergence and development of the \#justice4zakzakie hashtag illustrates what Papacharissi (2015) described as characteristics of online activity that can make a hashtag/movement having a significant political effect, namely serving pre-mediation, gaining popularity because of homophily and because of sharing patterns that resemble word of mouth sharing, and the fact that it is about an incident of national, yet local, interest. At the time of writing, "six people, including the two shop owners and four policemen, stand accused of inflicting fatal bodily harm, a charge all deny" (Smith 2020). The trial was originally scheduled for late 2020, but given concerns over public health, it is put on hold. The \#justice4zakzakie hashtag remains active, and it is now used to report instances of homophobic bullying, racism, as well as discriminations against LGBTQI+ individuals and groups.

Through this paper, I proposed homoterrorism as a construct that can provide an understanding of extreme acts of violence against the non-heterosexual Other, especially when such acts are framed as essential to the precipitation of national cohesion. I provided the case of Zak Kostopoulos as an example of applying homoterrorism as an analytical tool, and I also suggested Twitter activism as a possible way to challenge and subvert it. It is, however, evident that homoterrorism needs to be studied further. Possible foci include defining its parameters, presenting a systematic analysis of its characteristics, and providing a rigid framework that enables scholars to apply it when analysing cases similar to the one of Zak Kostopoulos's incident. I encourage further scholarship in relation to defining homoterrorism further, 
and I argue that it is a productive construct in that it sheds light not only on the violent acts themselves, but most importantly on systemic processes that justify such crimes as inevitable. 


\section{References}

Botan, Carl. H. 2018. Strategic Communication: Theory and Practice. Hoboken: Wiley-Blackwell.

Bruns, Axel. and Tim Highfield. 2012. "Blogs, Twitter, and breaking news: The produsage of citizen journalism." Pp. 15-32 in Producing Theory in a Digital World: The Intersection of Auduences and Production in Contemporary Theory, edited by A. R. Lind. New York: Peter Lang.

www.cfr.org, "Greece's debt. Councul on Foreign Relations." https://www.cfr.org/timeline/greeces-debt-crisis-timeline. Accessed January 2, 2021.

Chadwick, Andrew. 2013. The Hybrid Media System: Politics and Power. London: Oxford University Press.

Drucker, Peter. August 31, 2016. "Homonationalism, heteronationalism and LGBTI rights in the EU." Public Seminar. https://publicseminar.org/2016/08/ homonationalism-heteronationalism-and-lgbti-rights-in-the-eu/. Accessed December 3, 2020.

Duggan, Lisa. 2003. The Twilight of Equality?: Neoliberalism, Cultural Politics, and the Attack on Democracy. Boston: Beacon Press.

Erickson, Ingrid. 2010. "Geography and Community: New Forms of Interaction Among People and Places." American Behavioral Scientist. 53 (8): 1194 - 1207.

Francoeur, Adam. 2007. "The Enemy Within: Constructions of U.S. Immigration Law and Policy and the Homoterrorist Threat." Immigration and Nationality Law Review. 28: 55-86.

Grusin, Richard. A. 2010. Premediation: Affect and Mediality after $9 / 11$. New York: Palgrave.

Hamdy, Naila. 2010. "Arab Media Adopt Citizen Journalism to Change the Dynamics of Conflict Coverage." Global Media Journal: Arabian Edition. 1 (1): 3-15.

Hay, James. 2003. “Unaided Virtues: The (Neo-)liberalization of the Domestic Sphere and the New Architecture of Community." Pp. 165-206 in Foucault,
Cultural Studies, and Governmentality, edited by J. Z. Bratich, J. Packer, and C. McCarthy. Albany: State University of New York Press.

Howard, Philip. N. 2011. The Digital Origins of Dictatorship and Democracy: Information Technology and Political Islam. London: Oxford University Press.

Howard, Philip. N. and Muzammil, M. Hussain. 2013. Democracy's Fourth Wave? Digital Media and the Arab Spring. New York: Oxford University Press.

Herman, Edward. S. and Noam Chomsky. 1988. Manufacturing Consent: The Political Economy of the Mass Media. New York: Pantheon.

Jaffe, JoAnn., Amy, A. Quark. 2006. “Social Cohesion, Neoliberalism, and the Enterpreneurial Community in Rural Saskatchewan." American Behavioral Scientist. 50 (2): 206-225.

Jansen, Bernard. J., Mimi Zhang, Kate Sobel, and Abdur Chowdury. 2009. "Twitter Power: Tweets as Electronic Word of Mouth.” Journal of American Society for Information Science and Technology. 60 (11): 2169-2188.

Jenson, Jane. 1998. Mapping Social Cohesion: The State of Canadian Research. Ottawa: Canadian Policy Research Networks.

Papacharissi, Zizi. 2014. Affective Publics. New York: Oxford University Press.

Papacharissi, Zizi. 2015. "Affective Publics and Structures of Storytelling: Sentiment, Events and Mediality." Information, Communication, and Society. 19 (3): 307-324.

Phelan, Shane. 2001. Sexual Strangers: Gays, Lesbians, and Dilemmas of Citinzenship. Philadelphia: Temple University Press.

Płonecka, Marta. 2017. "Negative Sexuality as a Passive Social Attitude." Adeptus. 9. https://doi. org/10.11649/a.1356. Accessed January 1, 2021. 
Poulopoulou, Eleni Maria. 2019. "Public Queer Trauma in Contemporary Greece: Affective Atmospheres and Queer Public Cultures, the Case Study of the Murder of Queer Activist Zak Kostopoulos." MA Thesis. Department of Media and Culture Studies, Ultrecht University, Ultrecht.

Puar, Jasbir. K. 2007. Terrorist Assemblages: Homonationalism in Queer Times. Durham: Duke University Press.

Samoilenko, Sergei. A. 2020. “Shaping Nation Image: Contemporary Issues in Framing Research." National Resilience, Politics and Society. 2( 1): 51-66.

Schlesinger, Philip. 1991. "Media, the Political Order and National Identity." Media, Culture \& Society. 13 (3): 197-308.

Schonfield, Erick. June 8, 2010. "Costolo: Twitter now has 190 million users tweeting 65 million times a day." TechCrunch. https://tcrn.ch/30Hr1Nm. Accessed 25 December, 2020.

Smith, Helena. December 20, 2020. "Greek LGBTQ+ rights: "It was a lynching. No other way to describe it." The Irish Times. https://www.irishtimes.com/news/ world/europe/greek-lgbtq-rights-it-was-a-lynchingno-other-way-to-describe-it-1.4442104. Accessed 25 January 2021.

The Press Project. September 29, 2018. "Distortions and cover-ups in the Zak Kostopoulos case." The Press Project. http://bit.ly/2QkhZRp. Accessed 21 November 2020.

Van Dijck, Jose. 2013. The Culture of Connectivity: A Critical History of Social Media. New York: Oxford University Press.

Vis, Farida. 2013. "Twitter as a Reporting Tool for Breaking News.” Digital Journalism. 1(1): 27-47.

Weller, Katrin., Axel Bruns., Jean Burgess., Merja Mahrt., and Cornelius Puschmann. eds. 2013. Twitter and Society. New York: Peter Lang.

Yardi, Sarita. and Danah, Boyd. 2010. "Dynamic Debates: An Analysis of Group Polarization Over
Time on Twitter." Bulletin of Science, Technology, and Society. 30 (5): 316-327. 